\title{
On ideas of evolution and the evolution of ideas: communicating traditions of scientific enquiry
}

\author{
Nick Winder ${ }^{1 *}$, Isabelle Winder ${ }^{2,}$ Bruce Jefferson $^{3}$, \& Paul Jeffrey ${ }^{3}$ \\ ${ }^{1}$ Agora for Biosystems, Sigtunastiftelsen, Sigtuna, Sweden \\ ${ }^{2}$ School of Biological Sciences, Bangor University, UK. \\ ${ }^{3}$ School of Applied Sciences, Cranfield University, UK. \\ *Corresponding Author - Email: complex@newcastle.ac.uk
}

\begin{abstract}
That there was variation in the theories expounded by the major early thinkers on evolution is well established. What is less effectively articulated is how their intellectual ambitions and approaches to interpreting evidence reflect a deep-rooted difference in their views on what sort of systems, and problems evolution deals with; insights which speak directly to contemporary debates about how we communicate the nature of science with consequences for learning practice. We provide a re-reading of the perspectives adopted by those who formulated the central concepts of evolutionary theory to expose slender but persistent differences of emphasis. Our analysis contrasts the approaches to enquiry of three voyaging naturalists; Charles Darwin, Thomas Henry Huxley, and Alfred Russel Wallace. This potted history is used to illustrate the relationship between different traditions of scientific enquiry, specifically the natural philosophy approach characteristic of Wallace's work and the later Neo-Darwinists; Huxley's more empirical, natural history approach that anticipated punctuated equilibria, and Darwin's emphasis on agency and choice, which suggests a more humanistic mind-set. These understandings are used to propose a model of the structure of evolutionary science which has broader value as a motif for exploring and communicating the transitions between different modes of enquiry.
\end{abstract}

\section{Introduction}

The social history of evolutionary theory has always been a fecund source of intellectual debate and disputation. At times contentious, controversial, and revisionist, writings on Darwin and his contemporaries offer ever higher resolution interpretations of how the central ideas of evolution were constructed, argued, and communicated. However, beyond the mundane detail of who said what, when, and why, these insights have a second, perhaps less obvious, but equally valuable significance in helping us understand the interplay between assumptions, observations, and theory. A mastery of how paradigm, epistemology and ontology shape both theory building and understanding is important for learners and researchers. It is only in fields where we have detailed chronological commentary on the development of thought, concepts, and models that sufficient evidence is available to enable robust formulation of these relationships. Evolution is one such field and the relationships between the ideas of three seafaring naturalists, Charles Darwin, Alfred Russel Wallace and Thomas Henry Huxley, is particularly enlightening. Although the contributions of all three have become rather obscured by scientific creation-myths, a re-evaluation of their attempts to reconcile their scientific, spiritual, and political convictions with both their own and each- 
others' emerging understanding of evolutionary processes offers some stimulating insights into the structure of scientific enquiry.

Darwin, Huxley and Wallace were scientific outsiders - seafaring naturalists catapulted to fame in the decades following the birth of nations uprisings of 1848 that marked the transition to post-revolutionary nationhood in Western Europe. All three of our subjects became celebrities and were elected Fellows of the Royal Society, but their influences on subsequent developments were very different. Our ambition is to both explain how their ideas differed (using a number of vignettes exploring how they viewed elements of evolutionary theory) and map the differences onto a broader, systems model of epistemological traditions which might cultivate improved understandings of knowledge paradigms. Interest in the subtleties of theory development surface periodically in mature societies which seek to appreciate and learn from the history of ideas. Our contribution offers an opportunity to rejuvenate several areas of debate around variable and not necessarily complementary ways of thinking about the relationship between the physical and conceptual in theory building (as lucidly articulated by Ruse, 2010 and Fagan, 2007) as well as the role of science in the development of worldviews in society (Matthews, 2009). Importantly it also offers education practitioners an abstract device for communicating and exploring the structural relationships between different ways of understanding the world; an emerging topic of some importance in contemporary science curricula (Kampourakis \& McKomas, 2010). By drawing out subtle differences in worldviews and associated interpretations of the nature of science within an (ostensibly) single discipline we demonstrate some of the 'heuristic power' that results from a shift away from a homogeneous view of the nature of science towards an outlook informed by the specificities of a scientific field (Schizas et al., 2016).

\section{Darwin and plesionics}

The discipline of biology came into being at the end of the $18^{\text {th }}$ century. Where natural history had focussed on descriptions and static form, the acknowledged pioneers of biology, Gottfried Treviranus (1776 -1837), and Jean-Baptiste de Lamarck (1744 - 1829), tried to integrate natural history with natural philosophy, the study of process and transformation. Both men had been evolutionists in the sense that they believed species were mutable. Treviranus (1802) believed that species were super-organisms with a life-cycle of birth, reproduction and death. Lamarck (1802) had argued that evolution consisted of the co-adaptation of organisms to their physical neighbourhood. From the outset, the new discipline of biology had to integrate two sub-disciplines, morphology (the study of form) and physiology (the study of process). To speak of insect feeding-behaviour as physiology posed no problem because everyone knew what the insect was that did the feeding; but to speak of evolution as physiology begs questions about what actually does the evolving. It is easy to speak of the species as a sort of taxonomic super-organism, but the boundary judgements that delimit species are much less robust than those that define individual beetles. If biology were to become established as a unified science of life, the species problem would have to be resolved.

Charles Darwin is the first of the three voyaging naturalists at the heart of our story. Although his grandfather, Erasmus Darwin, had believed species were mutable, the younger Darwin's approach was broadly morphological and static. In his later work, however, Darwin realised that biology would need a species definition that could be applied without loss of generality 
to people, plants and animals and would accommodate the mass of evidence demonstrating that biological systems could evolve. He was also a naturalist in two senses of the word: he was interested in living things and the patterns they created in space and time and was also committed to naturalism, the belief that scientists should never appeal to super-natural agency as a causal explanation. When Darwin wrote about the descent with modification of animals under domestication, he was writing about a natural process. This is a significant difference between Darwin and Lamarck. Lamarck, the natural philosopher, believed evolution was a process of adaptation to the physical environment. Darwin understood that, for Lamarck's vision to be realised, biology had to be broad enough to cover the more complex processes involved in adjusting to a socially constructed landscape. Males became adapted to the choices and caprice of females and pollinators to plants, just as horses became adapted to the demands made of them by their jockeys. Artificial selection is natural.

Darwin's theory was closer to Lamarck's than Treviranus'. If evolution was the physiology of some super-organism, that super-organism was not a species, but a populated neighbourhood. The result was a plesionic model (from the Greek for 'neighbour' - plesion). Darwin argued that each corporeal organism was embedded in an open interval of space-time where it interacted with other organisms. We should emphasise that these terms are not Darwin's. Darwin did not even have words to describe ecology, ethology (the study of behaviour) or co-evolution. In Origin, Darwin distinguished the mutual relations of organic beings - we would call it 'taxonomy' or 'systematics' - from the mutual interactions of organic beings, i.e. ecology and ethology.

In Darwinian theory there are no less than three levels of organisation. First, there is the individual level. Each organism has a special (individual) and general (racial) memory and must struggle to exist. Second, there is the plesionic level, where a complex landscape of threat and opportunity creates a selective milieu where racial memories are winnowed. Finally, there is an emergent pattern that describes stable taxonomies of species and forms. There is no natural selection at the level of the individual. Natural selection is an aggregate phenomenon that can only be valorised within populations of individuals. Racial memories diverge to create species-like grades of organisation at a higher level of aggregation. The reason botanists, zoologists, ecologists and biogeographers cannot agree a universal definition of a species is that species boundaries are emergent structures shaped by complex accidents of history and geography on at least two space-time scales.

Every Darwinian system operates on three levels. There is a micro-scale of events and ethology, a synergetic conjuncture of plesionic interaction that allows us to speak about selection and processes, and a macro-scale where the deep time perspective allows us to construct a locally stable, but globally dynamic typology. Darwinian systems can operate so far from equilibrium that they are potentially dynamic at all three levels. The ecodynamic interactions of populations create a network of threats and opportunities that shape and reshape processes at the plesionic level. These processes generate patterns in space and time that can be used to characterise species and their attributes.

\section{Wallace and Neo-Darwinism}

The Darwin-Wallace Papers were published by the Linnaean Society of London in 1858 and contained contributions from both naturalists on the process of variation and natural selection. One of the most striking features of Wallace's contribution to the Darwin-Wallace papers is 
his insistence that Lamarckian inheritance is a discredited theory. Unlike Darwin, Wallace believed that natural selection only affected racial memory. There was no inheritance of acquired characters. Both Wallace and Darwin were hard selectionists in the early days. Darwin's understanding of natural selection softened through time while Wallace's hardened.

Among Wallace's books on evolution were Darwinism (1889) and The World of Life (1910) Here, Wallace makes it clear that he considers natural selection and artificial selection to be different types of phenomenon. He also has very little faith in the role of sexual selection and none at all in Lamarckian inheritance. He marshalled evidence from August Weismann (1834 - 1914) and Francis Galton, (1822 - 1911) among others, to support this view. Perhaps the most striking feature of the arguments presented in Darwinism is that Darwin himself would not qualify as a Darwinist. Like Darwin, Wallace assumes that organisms exist. Unlike Darwin, he also assumes that they can be organised into species-like populations using a combination of morphological and physiological attributes. In this way, Wallace effectively lays the foundations of population biology. Although he knew nothing about genetics, a Wallace species was a population of morphologically similar animals all potentially capable of exchanging racial memories by mating. Natural selection was a constraint that winnowed the population and forced animal populations into closer conformity with their natural environment. It was co-evolutionary in the sense that predators, competitors and food sources made a difference, but there is no emergence in Wallace's model. There are populations of individuals that can be organised into species that are transformed by natural selection. Species are persistent things whose identity is conserved and modified through time.

Wallace believed that human intelligence was qualitatively unlike that of animals. Human intelligence could only be explained in terms of some universal intelligence that seeded the world with agents, capable of evolving into higher forms. Speciation could be explained purely in terms of natural selection driving populations apart. Mate choice, agency and patterns of inter-species co-operation were not natural phenomena and so could not be incorporated into a scientific theory. This was a significant point of disagreement between Darwin and Wallace. Darwin felt he could explain the emergence of human intelligence and biogeographic 'species' by relaxing natural selection enough to create a two-level, fast / slow dynamic. Our higher cognitive function and moral scruples, for example, might actually place those who possess them at a small disadvantage compared to more selfish individuals. However: "...these faculties have been chiefly, or even exclusively gained for the benefit of the community; the individuals composing the community being at the same time indirectly benefitted." (Darwin, 1871; 153). This model of cognitive evolution cannot be sustained in a world where natural selection is inexorable and any slip results in death and Darwin (1871; 146) acknowledges that, "in the earlier editions of my 'Origin of Species' I perhaps attributed too much to the action of natural selection or the survival of the fittest."

There is a fine symmetry between Darwin's ideas and Wallace's. Darwin started off weakly religious and unconvinced by $18^{\text {th }}$ century ideas about evolution. In one sense he was forced to become an evolutionist by the mass of evidence. His early work on the species problem led him to become a generalist, a hard selectionist and a Lamarckian. One cannot understand botany or ethology without considering the possibility that personal memories can be passed between generations. Darwin grew more agnostic as he grew older and his work on human cognition obliged him to soften his position on natural selection. Wallace's early attitude seems to have been anthropocentric but more or less atheistic. He went off on his travels seeking evidence that would support evolutionary theory (Beccaloni and Smith, 2008) He was 
not a generalist and did not really care about the species problem. Wallace's intellectual development passed Darwin's in the 1860s, but Wallace was travelling in the opposite direction. In old age he became increasingly convinced that human creativity implied the existence of a universal intelligence (Wallace 1910).

Where the younger Wallace had been a naturalist in the sense that he did not build god into his model as the ultimate cause of everything, the older Wallace was a spiritualist who kept the natural and super-natural domains apart by building strong selective constraints into his theories. That hyper-selection eliminated adaptive potential, making it hard to explain the emergence of co-operative behaviour, agency and human cognition. Wallace's solution was to invoke a god of the gaps, a god invented to explain all the emergent patterns that could not be explained by hard selection. Darwin, on the other hand, started off with a clockmaker god, who created the machine, seeded it with a few species and then exited stage left, leaving the universe to its own devices. He did not need Wallace's god of the gaps because there was enough adaptive wriggle-room in the model to explain the evolution of flexible, adaptive behaviour and higher cognitive function.

By the later $19^{\text {th }}$ century there were two broad flavours of Darwinian theory. Wallace's version was highly constrained, mechanistic and broadly predictable. It can be thought of as a 'natural philosophy' model, comparable to contemporary developments in classical physics. This model, the fore-runner of what we now call 'Neo-Darwinian' theory, could be used ex post to explain evolutionary trajectories with the wisdom of hindsight and many biologists believed these insights could be generalised to the ex ante perspective. Causal processes were time-invariant. In Wallace's understanding of natural science, every natural effect had an antecedent cause. The future was immanent in the past and hence predictable. Wallace understood that the single greatest challenge to this natural philosophy model was the evolution of agency and human cognition, which could not be explained in terms of constraints and time-invariant processes, so he invoked a god-agent to take up the slack. That which could not be predicted using natural philosophy methods had to be explained in terms of some universal intelligence. The Darwinian model, on the other hand, was agnostic and time-asymmetric. Darwin treated organisms as plesionic agents able to achieve a co-operative synergy that could change the evolutionary trajectory. Consequently, the past could be explained in terms of causal constraints, but the future was locally unpredictable. This distinction of time-symmetric natural philosophy and time-asymmetric humanism became manifest as a paradigmatic tension that effectively pushed biologists like Darwin (atheistic humanist) and Wallace (theistic natural philosopher) beyond the pale of mainstream science.

\section{The Darwin-Huxley Synthesis}

Like Darwin, Thomas Henry Huxley started his career as a voyaging naturalist sceptical about evolution. He was surgeon's mate and ship's naturalist aboard the Rattlesnake, a brilliant anatomist who saw the key to understanding vertebrate diversity in the morphological approach. He was interested in the idea that there was a basic taxonomy of animal groundplans, a little like the chemist's periodic table or Goethe's (1790) theory of plant archetypes (Urpflanze). Darwin introduced Huxley to evolutionary ideas and, although initially sceptical, he was won over. Huxley $(1862,1863)$ made substantial contributions to anthropology in both its morphological and physiological manifestations. Huxley believed that, if human cognition were to be studied as a natural phenomenon, rather than as a gift from god, one 
could not afford to treat science as a source of gnosis, i.e. as dependable knowledge of things as they really are (Huxley 1884). Like Darwin, Huxley's approach to consciousness was phenomenological, based on a Neo-Kantian belief that all human knowledge is derived from phenomena (from sense-data filtered, as it were, by our animal senses and shaped by social learning). Like Wallace, Huxley had reservations about Lamarckian inheritance (Huxley 1878 ) and was also somewhat sceptical about Darwinian gradualism - natura non facit saltum (nature doesn't make jumps).

Darwin had used non facit saltum as an axiom that immunised his theory against empirical refutation. If species changed rapidly, the boundaries of species were potentially well-defined and Darwinian ideas seemed more speculative and equivocal. Huxley, in contrast, was deeply committed to the ugly facts that slay beautiful theories (Huxley 1870). The geological record does indeed make jumps - Georges Cuvier $(1769$ - 1832) had speculated that the creator had swept all life away and re-created it afresh - but Huxley (1878) dismissed Cuvier's interpretation and criticised him for knowing so little about embryology. Geologically speaking, he argued, nature does make jumps. The Darwinian model worked well within a geological epoch, but not so well between these step-changes. In addition to collecting evidence of step-changes over geological time, Huxley also described instances of small-scale jumps in the form of a polydactylous family and the so-called Ancona sheep. These mutations become manifest as discontinuous leaps between generations. They are not genetic mutations as $21^{\text {st }}$ century geneticists would understand them, but chance combinations of rare genes, often emerging in small, interbred populations. Huxley called these morphological jumps 'saltations'.

While Darwin, rather implausibly, used the imperfections of the fossil record to justify his assertion that nature did not really make jumps, Huxley accepted the gaps as a source of useful information about evolution. His 'saltationism' implied a stick-slip dynamic in which short periods of relative stability were punctuated, as it were, by catastrophic flips that swept species, families and classes away and replaced them with new forms. In February 1894 he wrote a letter to William Bateson containing the words: 'I see you are inclined to advocate the possibility of considerable "saltus" on the part of Dame Nature in her variations. I always took the same view, much to Mr. Darwin's disgust, and we used often to debate it.'

Where Wallace's Neo-Darwinism was never far from equilibrium and Darwin's theory, though far from equilibrium, was constrained by non facit saltum, Huxley's reworked model was locally catastrophic. The whole three-level system could collapse and be replaced by a new one so fast that no intermediate forms would be found in the fossil record. The species problem is much less troubling in a saltatory universe of discourse. There is no reason to doubt that different types of species would emerge in different circumstances, but no need to agonise about the species problem. Species are thereby morphologically robust categories.

\section{The debate on epigenesis}

As an example of how the slender and subtle disparities in knowledge-seeking agendas can generate contrasting explanations of identical phenomena we turn to the disputation between Huxley and Darwin about the nature of inheritance. When Huxley was invited to write an article on evolution for Britannica he began by linking evolution to epigenesis - from epi (above) and genos (origin). Later $18^{\text {th }}$ century naturalists had tended to think in terms of organisms packed inside each other like Russian dolls. When Eve (or Adam) was created god 
put the germs of her (or his) offspring inside. The germs of the germs of their grandchildren were inside those and so on. This theory, sometimes called emboitement, implied that the possibility space of future evolution was well-bounded. The germs of all creation were present at the beginning of time. The only scope for contingency was in decisions about which of these germs would thrive and which would die without issue and, since god had that nailed down too, the principal difference between the human and the god's eye view of nature was imperfect knowledge.

Although this is clearly a religious way of looking at the world, it contains the germs of the classic approach to natural science. The universe of possibilities is closed. Although we who are trapped in space and time do not know what has happened and will happen, gnosis is theoretically attainable because reality is independent of human knowledge and belief. To believe that reality is bounded in this way does not imply that gnosis is actually attainable. Classic science is an unending quest for the holy grail of gnosis. The antithesis of classic science is the romantic approach. Romanticism is more humanistic because it holds that humans are co-creators of reality. Romantic science does not necessarily imply gnosticism either. A romantic extremist might be tempted to slip into solipsism, the belief that reality is a figment of the human imagination, but most romantics simply accept that humans and some other organisms are agents and agents can change the course of history.

Epigenesis is the belief that the organism is not merely fabricated from some genetic blueprint, but is actually assembled from information and materials gathered from both parents and from the physical environment in which the organism develops. Darwin's (1868) model of heritable change, called pangenesis, is an epigenetic theory of inheritance. It has the organism created from a blend of gemmules derived from father and mother. Epigenesis creates an open universe of possibilities in which the future of an evolutionary system is unbounded and a priori unknowable.

An epigenetic system is a complex, self-organising or self-sustaining structure (Waddington 1953; Bateson 1979; Maturana and Varela 1973) which is brought into being by a synergetic friction between an organism and its environment. A system can be epigenetic without necessarily being plesionic. In placental mammals, for example, the mother's uterus provides a complex environment within which the baby develops. There is no plesionic (self / other) interaction, merely an epigenetic relationship between the two. If there were twins in the uterus, the system would be both epigenetic and plesionic. Clearly, any organism that develops in an epigenetic context is potentially capable of emergent behaviour, but the probability of emergence is greatly increased if the organism is interacting with neighbours that are themselves capable of acquiring new types of behaviour.

Ludwig Von Bertalanffy gave us a useful word to describe some epigenetic systems, equifinality. A poppy seed, if it develops at all, will always develop into a poppy, not a cabbage or a caterpillar. If it is short of nutrients, it will grow into a stunted poppy, but it will still be a poppy. Poppy seeds are equifinal systems. Bertalanffy speculated that ecosystems and social systems were equifinal too and so they are - sometimes. Equifinal systems tend to be almost isolated from their neighbours. Like the developing foetus, they are enclosed in a womb, bathed in amniotic fluid and buffered by the homeostatic mechanisms that sustain the mother. Darwin's Galapagos islands were also almost isolated. Flows of material and information between them were so weak that they were almost closed systems, creating themselves from an internal genetic blueprint - the founder population. Systemic openness 
and free exchange of material or information between neighbours undermines the principle of equifinality.

This is arguably the principal difference between Wallace's ideas, which formed the foundations of Neo-Darwinian theory and the Darwin-Huxley or saltatory model. The former is genetic; the latter is not merely epigenetic, but plesionic. From the Darwin-Huxley perspective equifinality is an emergent phenomenon that must be explained. Interactions between the cells of the human body offer a useful example for this. These cells are constrained by chemical gradients and bounded into almost-closed systems called organs. These boundaries weaken patterns of plesionic interaction, replacing a strongly competitive dynamic with a more co-operative mode of operation. If that co-operative dynamic breaks down, the organism's health is compromised.

At the time of writing, the Neo-Darwinian and Darwin-Huxley models seem to be ranged in paradigmatic opposition. Time has not stood still, of course. Huxley would have been troubled by the work of ethologists and evolutionary psychologists in the $20^{\text {th }}$ century. Wallace would have been astonished and no doubt delighted by the success of Mendelian genetics, though one suspects he might have been troubled by its simplistic treatment of biogeography and the removal of the abstract god-agent he believed was needed to explain unpredictable phenomena.

\section{Study domains, belief and agnosticism}

The three distinguished naturalists whose ideas we have been describing were each struggling to place anthropology, the natural history of our own species, onto a sound scientific footing. Each was tip-toeing around the problem of agency and human cognition, trying to form a stable bridge of theory and evidence between the humanities and natural philosophy. That bridge must be able to explain time-asymmetric phenomena, creativity, and innovation without appeal to holy writ or dogma. The same rules must apply to the poet, the orang-utan, the beetle, and the bacterium without loss of generality.

Thomas Henry Huxley (1874) clearly believed that the empirical evidence took absolute priority over abstract ideas and logical consequences, which he dismissed as 'scarecrows of fools and beacons of wise men" (Huxley, 1882, p247). But Huxley's empirical imperative does not serve us well in this context because truth is an ideational 'thing' and so are beliefs. Humanists and theologians have long understood that there may be three types of thing material things like goods, ideational things like risk and symbolic things like credit ratings. These types of thing interact in a complex way. If you see a polity's credit-rating (symbol) you may revise your ideas about risk (ideational) and, in so doing, develop a new pattern of behaviour which, taken in concert with other people's actions, costs lives and destroys ecosystems (material). This triangular relationship between object, idea and symbol is the basis of all textual interpretation and is sometimes called the 'hermeneutic triangle'.

It is only possible to ignore these differences in the nature of things in study-domains where categories are robust. Isaac Newton, for example, developed a stable taxonomy of masses, bodies, forces and the rest. Once it was stable, he could take it for granted and work on the physiology of the solar system or a projectile. Natural historians cannot do that. Our conceptual taxonomies change; partly because our opinions change, and partly because new empirical evidence often renders them obsolete. The difference between natural history and natural philosophy has to do with the stability of named classes. Once you venture into the 
realm of humanism and agency, classes become much less stable and the empirical evidence is much less significant than patterns of discourse and opinion.

When humanists and natural philosophers are allowed to ignore the natural history perspective, they can easily get bogged down in paradigmatic squabbles. The natural philosopher thunders that 'scientists' deal with facts and non-scientists with delusions. The humanists reply that the only reason physicists win prizes is that god gave them all the easy problems to solve. From a naturalist's perspective, the disease that wipes out a family is not an opinion or a delusion. It was a thing when people believed in miasma and remains a thing now we believe in infectious agents. We know it is a thing because it changes the morphology and physiology of living organisms in an interpretable way. A nation's credit rating is a thing for the same reason. Perhaps it only exists by negotiation and common consent, but a developing country with a poor credit rating is an uncongenial place. If it were a delusion, people would not be dying as a result.

\section{Intellectual and operational knowledge}

There is no scholarly consensus about the shape of science. What we offer below is an attempt to construct a phenomenological map or image of the intellectual landscape that is science, drawing on examples from our three voyaging naturalists' claims to knowledge and belief to locate them on this map. Each of those naturalists had a slightly different perspective on the problem of human cognition. Darwin's approach to natural history was humanistic in the sense that he understood that we humans create and re-create the life-support systems that sustain us. Unlike Wallace, he believed this was a natural phenomenon; an extension of the adaptive potential of other animals. Wallace's approach to ecology was that of the natural philosopher, treating the environment as a set of near-equilibrium 'boundary constraints' to which organisms became adapted by natural selection. Huxley was a brilliant morphologist and anatomist whose approach was primarily empirical.

If one works with scientists long enough, one finds that different types of scientist are interested in different types of thing and these interests tend to become manifest as different types of judgement. Charles Darwin, for example, was fascinated by conceptual taxonomies, morphology and boundary judgements. He was not merely interested in species operationally; they fascinated him at an abstract, intellectual level. Origin, as we have observed, is about the emergence of species-like patterns. In contrast, Wallace saw species as scientific axioms and wanted to know how pre-existing species were transformed through time. This physiological approach to species was extended even further by later Neo-Darwinists, whose approach was broadly mathematical and predictive. Where Wallace considered the study of human cognition and purposeful action to be scientifically intractable, Darwin and Huxley did not. Huxley did not share Darwin's interest in the species problem or human agency, but was deeply interested in cognition. He considered human values and purposes to be cognitive echoes - static left on the neural networks that gave us the impression of purposeful action. Humans were conscious automata. We were not machines, whose behaviour could be deduced from mathematical laws, but there was no Cartesian ghost in the human body and no such thing as free will. Later Neo-Huxleyan biologists melded Darwin's ideas about species as emergent phenomena with Huxley's ideas about automatism. Conwy Lloyd Morgan (1922), for example, believed value-judgements in particular and cognitive constructs in general were emergent phenomena. Like Huxley and Darwin, the evolutionary psychologists 
believed evolutionary systems could not be predicted, ex ante, though evolutionary phenomena could be explained, ex post. Like the younger Wallace, Lloyd Morgan left room for a god-agent in his theories, but this was no god of the gaps that created the universe and seeded it with agents capable of acting creatively. Lloyd Morgan saw god as an emergent phenomenon - an unpredictable by-product of human and natural agency. Humans and godagents continually created and re-created each other, rather as humans and political institutions shaped and re-shaped each other through time.

\section{Mapping evolutionary science}

The description of plesionics introduced above suggests a spectrum of possible concerns for scientists operating in the domain of evolution stretching from a focus on self, subjectivity and experience to a focus on universe and timeless truth. These extremes may reasonably be thought of as romantic and classic respectively. Clearly our three evolutionists lived somewhere between these extremes. We can represent this spectrum by creating a grid that spans the range from classic to romantic science, divided into five cells (see Figure 1a). The centre cell we label natural history. To one side of natural history we put natural philosophy and, to the other, humanism. With reference to the plesionic system, humanists tend to be interested in the relationship between organisms, naturalists in the environment itself, and natural philosophers in the relationship between environment and what lies outside it.

Wallace, Darwin and Huxley are distributed across the middle of the grid, with Morgan in the humanistic mainstream. Wallace occupies the interface between natural history and natural philosophy. Most Neo-Darwinists are mainstream natural philosophers. Natural philosophy tends to use analytic method and symbolic reasoning to make ex ante predictions. Humanism tends to use discursive methods, ex post. We can represent this by modifying our grid so that it contains three rows representing discursive, analytic and empirical methods, and shading the centre of gravity (Figure 1b).

The shaded diagonal represents the sweet-spots in those disciplinary domains where operational, boundary and value judgments intersect and well-posed problems are located. Humanists tend to harmonise intellectual and operational truths by concentrating on self-other interaction and linking empirical and discursive methods ex post. Natural philosophers tend to achieve the same effect by focussing on the relationship between arena and universe and linking empirical to analytic method ex ante. Darwin, Huxley and Wallace all live in the middle of the diagonal stripe: Wallace to the left of centre; Huxley in the middle. NeoDarwinism and sociobiology belong to natural philosophy and, as such, live closer to the classic region. As we move from centre to right, we pass ethology, evolutionary psychology, critical scholarship and post-modern humanism. Political theory, pure mathematics, theology and metaphysics occupy the outer columns of the grid, often passing freely from one end of the grid to the other. Karl Marx, for example, treated intra-communal violence and dialectic as cultural universals and failed to distinguish his own political aspirations from the laws of nature (Marx, 1867). Sir Herbert Spencer treated inter-group warfare as a cultural universal and advocated a laissez-faire approach to sociology (Spencer, 1864). Theoretical physicists and philosophers often make the leap between ideas and universal truths and the transformation of scale required to do this is operationally significant.

As we pass from humanism, to natural history to natural philosophy, our attention shifts from the subjective and local to the objective and regional and on to the abstract and universal. If 
we extend that trend to right and left then on the right we have a sort of romantic extremism that considers things to be figments of the imagination; on the left a classic extremism that considers things to be pale shadows of some universal reality. Note that the boundaries between regions are dotted to show that they are fully permeable and indefinite. To strengthen the impression that there are no barriers to free movement on this grid, we will roll it and glue the edges together and then roll the ends of the tube round to create a torus (Figure 1).

a)

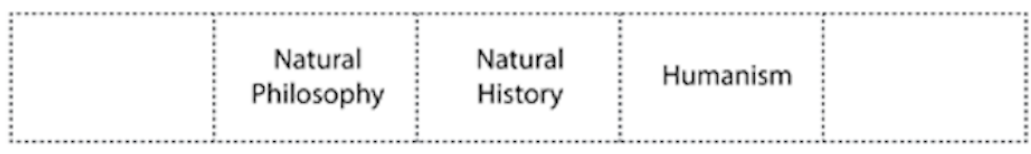

b)

\begin{tabular}{|c|c|c|c|c|}
\hline Discursive & $\begin{array}{c}\text { Discursive } \\
\text { Natural } \\
\text { Philosophy }\end{array}$ & $\begin{array}{l}\text { Discursive } \\
\text { Natural } \\
\text { History }\end{array}$ & $\begin{array}{l}\text { Discursive } \\
\text { Humanism }\end{array}$ & Discursive \\
\hline Empirical & $\begin{array}{c}\text { Empirical } \\
\text { Natural } \\
\text { Philosophy }\end{array}$ & $\begin{array}{l}\text { Empirical } \\
\text { Natural } \\
\text { History }\end{array}$ & $\begin{array}{l}\text { Empirical } \\
\text { Humanism }\end{array}$ & Empirical \\
\hline Analytical & $\begin{array}{c}\text { Analytical } \\
\text { Natural } \\
\text { Philosophy }\end{array}$ & $\begin{array}{l}\text { Analytical } \\
\text { Natural } \\
\text { History }\end{array}$ & $\begin{array}{l}\text { Analytical } \\
\text { Humanism }\end{array}$ & Analytical \\
\hline
\end{tabular}

C)

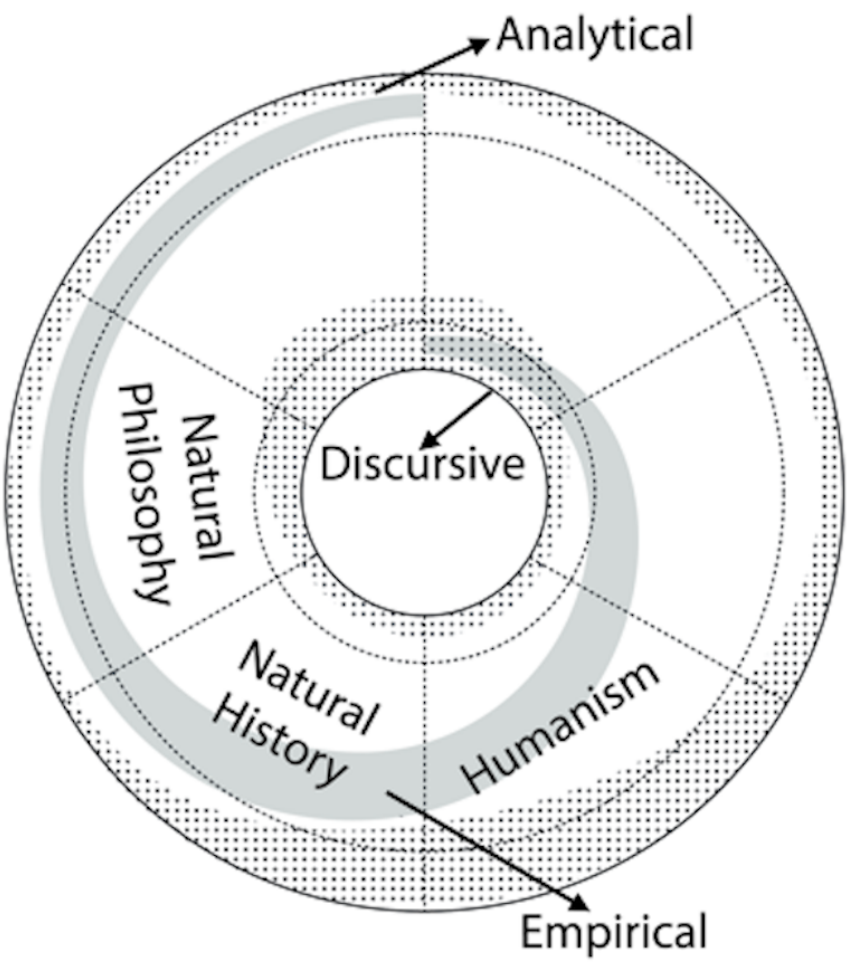

Figure 1: (a) The spectrum of science: from classic (right) to romantic (left), (b) a generalisation of the spectrum showing intellectual comfort zones for various scientific traditions, (c) the spectrum rolled into a torus to create a continuous landscape of scientific traditions. 
The torus is broadly agnostic near the bottom and gnostic near the top. Romantic and classic gnosticism butt up against each other here. It is possible to move across the dotted line at the top of the torus, but one is likely to experience an uncomfortable singularity or discontinuity between the study of the universal and the personal. This is where the dogmatic universalist meets the puritan; the romantic solipsist contends with the classic hyper-reductionist, and the political theorist gets confused about the distinction of value judgements from universal scientific laws. This model space is so constructed that no research project, community or individual can be represented as a unique point. We are represented by broad, sometimes discontinuous smears. Imagine Huxley, somewhere near the natural philosophy side of natural history, sincerely advocating an agnostic approach to science and being tempted by his own reforming zeal and the ethical issues to flip up to the top of the torus, stand on his soapbox and preach the universal importance of agnosticism.

The hermeneutic triangle is also evident within the toruss structure. Near the bottom of the torus the work is highly empirical. The distinction of object from idea from name is relatively clear. As you move up the right hand side into humanism, your scale of observation changes. You become more aware of physiology, the effect of purposeful action and accidents of history. Purposeful agency and teleology are significant here and physiology must deal with a narrative chain of events and rich description. The hermeneutic triangle flattens down to the point where material things fade into the background and the foreground is dominated by the relationship between symbols (words) and ideas. If you move clockwise up into natural philosophy, your scale of observation increases. Processes become time-symmetric and a machine-like, efficient (machine-like) cause comes into view. The work becomes more analytic and the hermeneutic triangle flattens once again, focussing attention on the relationship between symbols (particularly mathematical symbols) and ideas and pushing material evidence into the background.

The closer one gets to the top of the torus, the harder it is to distinguish morphology from physiology because the human experience of space and time is scarcely visible at all and we find ourselves arguing about universal truths. Universal truths are neither dynamic nor static; they are just true. There are only symbols and ideas up here in the gnostic domain. That terrible singularity where our ideas about the very large and the very small come into contact is an artefact of space-time perspective. We humans evolved in physical arenas. Our cognitive intuitions have been honed into conformity with the middle-range experience of everyday life. The closer we get to the top of the torus, the weaker the relationship between ideas and material evidence. The singularity at the top could be a political artefact, but it is also possible that it represents a conflict between two sets of cognitive intuitions, one of which deals with flat hermeneutic triangles linguistically, while the other tackles them from an analytic standpoint.

\section{The evolution of ideas and science education}

The model we have sketched here, though heavily simplified, fits the patterns one finds in the seminal literature of the 19th century and can be extended into the 20th century without much difficulty. The foregoing analysis provides a general summary of the key ideas needed to begin thinking about thinking. With a conceptual taxonomy that includes the elements of plesionics (environment, self, others and universe) we can begin to situate scientific 
endeavour in a human framework. Using these tools, we have been able to move from a picture of human interaction to a general model of science and we have begun to develop the latter to summarise problem spaces and the scale and emphasis of different scientific fields. The writings of three intellectual giants have helped us flesh out the similarities and differences between humanism, natural history and natural philosophy so as to provide a general model capable of supporting learning about the structure of and relationships between these scientific traditions.

Asking questions about what sort of pursuit science is, what its role in society is, and what assumptions about the role of knowledge and understanding imprint themselves on scientific practice is an important habit for both scientists and citizens. Understanding science as process is a frequent pedagogic terminus in this regard and the debates, controversies and paradignatic struggles which infuse the history of evolutionary science with both passion and intellectual challenge have provided rich pickings for scholars wishing to illustrate how science works. The musings of all three of our protagonists in particular deliver numerous opportunities for such learning (see Lyons 2010 for a well-articulated example). However, revealing the mutual influences between evidence and theory is only part of the challenge. Learners need to be taken beyond, into the non-trivial realm of why and how science serves humanity so that we can appreciate how different claims for the credibility and value of scientific endeavour are formulated and justified. Previous contributions to this broader canvass of the role which intellectual traditions play in shaping theory development and understanding have often failed to identify the educational prospects emergent from such insights. Sporadic contributions which have dallied with the pedagogic implications of how scientific endeavour is viewed by scientists (notable examples of which have come from Moran, 2006 and Maxwell, 2012) have recently been enriched by clear calls for educators to better incorporate understandings of the nature of science and epistemology in their curricula (Sandoval, 2014).

Even a cursory appreciation of how claims to knowledge and understanding are fashioned and defended by (often implicit) reference to wider frames of social and cultural reference provides an important starting point for learning about scientific method and the relationships between science and society and between scientific disciplines. Whilst the fact that the world's problems do not come in disciplinary shaped boxes is now widely recognised, the learning of skills and competencies to underpin interdisciplinary investigation is dependent on a deep appreciation of the natures and roles of science (Fortuin et al., 2011). Awareness of, and the ability to interpret and manipulate, the central tenets of theories and allied methods is a critical tool in the search for accommodation between different perspectives or approaches. An understanding of the nature of problems, how we might acquire knowledge about the world, the strengths and weaknesses of different forms of enquiry, and the knitting together of knowledge to support action are central to the emergence of well-rounded professionals (Puolimatka, 2008). The arguably as yet incomplete Mode 2 revolution in knowledge generation (Gibbons et al., 1994) is dependent on a new generation of scientists and practitioners who comprehend how variation in cognition, context, and preconception fuel disagreement and can explain how and why shades of meaning and interpretation emerge. The value of interdisciplinary endeavour is achieved not only through being able to bring methods from disciplines $a$ and $b$ to bear on the same problem but, perhaps more importantly, through understanding the epistemic and ontological tenets and assumptions which underpin the practice of and claims to legitimacy for those disciplines. 
The story of how Darwin, Huxley, and Wallace patterned their own ideas, skirmished with those of their adversaries, and struggled to harmonise their emerging theories with the paradigms which gave birth to them encourages us to think about the roles of assumption, uncertainty, and accommodation in scientific endeavour. It also tells us a lot about the need for improved communication across the boundaries which demarcate scientific paradigms and practice. Hence, such chronicles not only inform about the historical development of ideas but also exemplify scientific culture, helping to nurture enquiring, challenging minds. Although tools, techniques and storylines that can be used to elucidate the influence of intellectual traditions on theory development remain few and far between, the rather unconventional narrative and model offered in this contribution demonstrates that such aids can be compiled from relatively simple starting points.

\section{Acknowledgements}

We are grateful to Sheila Severn Newton and Zoe Griffiths for realising our rather untidy original sketches as beautiful line drawings.

\section{References}

Beccaloni. G., \& Smith, C. H. (Eds). (2008). Natural selection and beyond: The intellectual legacy of Alfred Russel Wallace. Oxford: Oxford University Press.

Bateson, G. (1979). Mind and Nature: A Necessary Unity (Advances in Systems Theory, Complexity, and the Human Sciences). New York: Hampton Press.

Bergson, H. (1907). L'Evolution Creatricse. Paris: Les Presses Universitaires de France

Darwin, C. (1859). On the origin of species by means of natural selection, or the preservation of favoured races in the struggle for life. London: John Murray.

Darwin, C. (1868). The variation of animals and plants under domestication. London: John Murray.

Darwin, C. (1871). The Descent of Man, and Selection in Relation to Sex. London: John Murray.

Darwin, C., \& Wallace, A. R. (1858). The Darwin-Wallace Papers. Available at: http://darwin-online.org.uk/converted/pdf/1858_species_F350.pdf accessed $07 / 12 / 17)$

Depew, D.J. (2010). Darwinian controversies: An historiographical recounting. Science and Education 19 (4-5), pp. 323-366

Fagan, M.B. (2007). Wallace, Darwin, and the practice of natural history. Journal of the History of Biology 40 (4) , pp. 601-635

Fortuin, K.P.J., Van Koppen, C.S.A.K., \& Leemans, R. (2011). The value of conceptual models in coping with complexity and lnterdisciplinarity in environmental sciences education. BioScience. 61(10), pp. 802-814

Gibbons, M., Limoges, C., Nowotny, H., Schwartzman, S., Scott, P., \& Trow, M. (1994). The New Production of Knowledge. London: Sage.

Goethe, J.W. von. (1790). The Metamorphosis of Plants.

Huxley, T. H. (1882). Science and Culture and Other Essays. New York: Appleton \& Co. 
Huxley, T. H. (1862). On the fossil remains of Man, Proceedings of the Royal Institution (1858-62).

Huxley, T. H. (1863). Evidence as to Man's place in nature. London: Williams \& Norgate.

Huxley, T. H. (1870). Biogenesis and Abiogenesis. in (1968) Collected Essays of Thomas H. Huxley, vol. 8, Discourses Biological and Gelogical. New York: Greenwood Press.

Huxley, T. H. (1874). On the hypothesis that animals are automata, and its history. In Huxley T.H. (Ed.), Method and results: Essays by Thomas H. Huxley (pp. 199-250). New York: D. Appleton and Co.

Huxley, T. H. (1878). Evolution in Biology. Encycopaedia Britannica, $9^{\text {th }}$ Edition.

Huxley, T. H. (1884). Agnosticism: a Symposium. The Agnostic Annual. London.

Huxley, T. H. (1889). Agnosticism. The Nineteenth Century. 25, pp169-94.

Kampourakis, K., \& McComas, W. F. (2010). Charles Darwin and Evolution: Illustrating Human Aspects of Science. Science \& Education. 19 (6-8), pp 637-654

Lamarck, J-B de. (1802). Recherches sur l'organisation des corps vivants.

Lyons, S.L. (2010). Evolution and education: Lessons from Thomas Huxley. Science and Education 19 (4-5) , pp. 445-459

Marx, K. (1867). Capital: Critique of Political Economy.

Matthews, M.R. (2009). Teaching the Philosophical and Worldview Components of Science. Science \& Education 18 (6-7), pp 697-728

Maturana, H. R. \& Varela, F. J. (1973). Autopoiesis and Cognition: the Realization of the Living. Dordrecht: D Reidel Publishing Company.

Maxwell, N. (2012). In praise of natural philosophy: A revolution for thought and life. Philosophia 40 (4), pp. 705-715

Moran, B.T. (2006). Axioms, essences, and mostly clean hands: Preparing to teach chemistry with Libavius and Aristotle. Science and Education 15 (2-4) , pp. 173-187

Morgan, C. L. (1921-22). Emergent Evolution. Gifford Lecture Series. Available on-line at https://www.giffordlectures.org/lectures/emergent-evolution (accessed $07 / 12 / 17)$

Puolimatka, T. (2008). Max Scheler and the idea of a well rounded education. Educational Philosophy and Theory. 40(3), pp. 362-382

Ruse, M. (2010). Darwinism Then and Now: The Divide Over Form and Function. Science \& Education. 19 (4-5), pp 367-389

Sandoval, W. (2014). Science Education's Need for a Theory of Epistemological Development. Science Education, 98 (3), 383-387.

Schizas, D., Psillos, D., \& Stamou, G. (2016). Nature of Science or Nature of the Sciences? Science Education. 100 (4), 706-733

Spencer, H. (1864). First Principles of a New system of Philosophy. New York: Appleton.

Treviranus, G. R. (1802). Biologie, oder Philosophie der lebenden Natur für Naturforscher und Ärzte. Göttingen: Röwer. 
Wallace, A. R. (1889). Darwinism: an exposition of the theory of natural selection with some of its applications. $2^{\text {nd }}$ Edition. London: Macmillan.

Wallace, A. R. (1910). The world of life: a manifestation of creative power, directive mind and ultimate purpose. London: Chapman and Hall

Waddington, C. H. (1953). The Epigenetics of birds. Cambridge: Cambridge University Press

Wilson, Edward O. (1998). Consilience: the unity of knowledge. New York: Knopf. 